九州大学学術情報リポジトリ

Kyushu University Institutional Repository

\title{
Effect of Heat Resistant Coating on the Drilled Hole Quality of Hybrid Fiber Reinforced Epoxy Composite
}

Kabir, Sarower

Department of Mechanical Engineering, Universiti Teknologi PETRONAS (UTP)

Ahmad, Faiz

Department of Mechanical Engineering, Universiti Teknologi PETRONAS (UTP)

Malik, Khurshid

Department of Mechanical Engineering, Universiti Teknologi PETRONAS (UTP)

Nosbi, Norlin

Department of Mechanical Engineering, Universiti Teknologi PETRONAS (UTP)

他

https://doi.org/10.5109/4150472

出版情報：Evergreen. 7 (4)，pp.530-537，2020-12. 九州大学グリーンテクノロジー研究教育センター バージョン：

権利関係 : 


\title{
Effect of Heat Resistant Coating on the Drilled Hole Quality of Hybrid Fiber Reinforced Epoxy Composite
}

\author{
Sarower Kabir ${ }^{1}$, Faiz Ahmad ${ }^{2, *}$ Khurshid Malik ${ }^{3}$, Norlin Nosbi ${ }^{4}$, Laurent GUI \\ LLAUMAT ${ }^{5}$ \\ 1,2,3,4 Department of Mechanical Engineering, Universiti Teknologi PETRONAS (UTP), Perak 32610, Mala \\ ysia \\ ${ }^{5}$ Ecole Nationale Superieure d' Arts et Metiers (ENSAM), 49035 Angers Cedex, France
}

*Author to whom correspondence should be addressed:

E-mail: faizahmad@utp.edu.my

(Received August 25, 2020; Revised November 14, 2020; accepted November 24, 2020).

\begin{abstract}
Drilling is considered an inevitable operation for joining components in automotive and aerospace industries. Hybrid fiber reinforced polymer (HFRP) composites have attained enormous attention due to their light weight and higher strength. In this study, HFRP composite was made of glass, carbon fibers and epoxy. The vacuum infusion molding technique is used to fabricate HFRP composites. Physical and mechanical properties of HFRP composites were analyzed according to ASTM standard. Heat resistant coating was made of conventional coating ingredients with fillers as a binder to enhance coating performance. This coating was applied on HFRP composite. Drilling performance was tested for HFRP and coated HFRP composites to examine the impact of coating of the composite in term of drilled hole quality. Results showed that density was reduced by $10 \%$ after applying the coating in HFRP composite. The tensile and flexural strength were found around $441.27 \mathrm{MPa}$ and $409 \mathrm{MPa}$, respectively. The coating was effective in terms of improving drilled hole quality by minimizing delamination factor. It was found higher with the increment of spindle speed and feed rate for both coated and uncoated HFRP composite samples. Coated samples showed less DF at the entrance as well as exit compared to uncoated composites.
\end{abstract}

Keywords: Heat resistant coating; HFRP, VIM, delamination.

\section{Introduction}

Composites are cutting edge engineering materials used in modern high technology products. High performance fiber reinforced polymer (FRP) composite materials are getting attention because of their advantage in producing lightweight structures. FRP composites was found to have competitive edge despite of their initial cost and considered more efficient and durable when it comes to severely corrosive environments ${ }^{1}$. The ease of design flexibility, corrosion resistant and mechanical properties have made composite materials as primary choice for automotive industries ${ }^{2)}$. In addition, possessing isotropic mechanical feature in three orthogonal direction, composite materials holds the attribute of low cost accessibility of reinforcement and ease of fabrication ${ }^{3)}$. The growing use of FRP composite materials in automotive and aircraft structural application requires drilling of holes makes it almost unavoidable operations for assembly/joining and repair purposes ${ }^{4)}$. Typically 100,000 holes are required in assembling of a small aircraft using mechanical fastener ${ }^{5)}$. But the problem associated with drilling of composite is delamination which is basically defined as the fiber pull/push out occurring a damage at the entry and exit of the composite. This defect is highly responsible in influencing mechanical properties of the component as well as making the parts unacceptable ${ }^{6}$. Flammability is one important parameter that limit the application of composite ${ }^{7}$. The fire attack towards FRP is another safety concern in composite structure because in such fire environment, the FRP system cannot resist a regular load because of the reduced loadbearing capacity ${ }^{8)}$. Fire performance of polymer composites is not satisfactory since their organic matrix resin tends to soften when heated resulting loss of mechanical properties.

In recent years, most of the literatures showed that a lot of work has been done in investigating the influence of drilling parameters such as cutting speed, feed rate, tool diameters, drill point angle etc. on the thrust force, torque, delamination and surface roughness of either steel or CFRP or GFRP or their hybrid. Carbon and glass fibers are the most chosen materials in aerospace and automotive industries because of their high specific strength and stiffness ${ }^{9}$. It was reported that drilling of glass fiber 
reinforced polymer leads to a several problems mainly the delamination problem. If the material is hard, delamination will be more; when the tools thrust is high, damage will be equally high ${ }^{10)}$. Daxi Geng et al. ${ }^{11)}$ reported in their research that delamination factor increased with the increased feed rate at any drilling parameters with various drill bits. The effects of cutting speed, feed rate, and point angle on delamination factor were analyzed using the models by generating response surface plots where researchers revealed that the delamination tendency decrease with increase in cutting speed and the study also suggested that low values of feed rate and point angle is better for reducing the damage in CFRP composite plate ${ }^{12)}$. $N$. feito et al. ${ }^{13)}$ investigated and concluded that lowering the feed rate reduces delamination. Maoinser et al. 14) concluded in his research that lowest spindle speed and feed rate resulted in lowest damage. Higuchi et al. 15) investigated the behavior of push out delamination while drilling composite laminates and concluded that the delamination is significantly affected by the thickness and materials of the bottom plies.

However, feed rate has been found the most influential parameters as it is generally responsible for resulting delamination on polymer composites. Moreover, due to the intricate application of drilling operation in various industries, it is important to look on the scopes of composite materials in fireproof application since no study on this has taken place. Heat resistant coating helps the underneath substrate by resisting heat penetration and ensuring quality surface finish of the parts.

In this study, we fabricated hybrid fiber reinforced polymer (HFRP) composites using vacuum infusion molding technique. The HFRP composite were coated with heat resistant coating of $2 \mathrm{~mm}$. Physical and mechanical properties were measured. Drilling parameters such as spindle speed and feed rate were varied to investigate the delamination factor arisen at entry and exit side of HFRP composite.

\section{Materials and methodology}

Materials, fabrication technique, coating preparation method and characterization are described in this section.

\subsection{Materials}

Carbon and Glass fiber was purchased from RP Products Sdn Bhd, Bandar Baru Seri Alam, Malaysia. Epolam 2040/2042 resin hardener was bought from Advance Altimas Sdn Bhd, Petaling Jaya, Selangor, Malaysia. Table 1 shows the fibers properties. Conventional coating ingredients such as expandable graphite (EG), boric acid (BA), ammonium polyphosphate (APP), melamine and halloysite nanotube (HNT) were purchased from Sigma Aldrich (M) Sdn Bhd. Malaysia. Zirconium phosphate was purchased from Sichuan Hongchang Plastics Indus. Co. Ltd. China. BE-188 (BPA) resin and H-2310 polyamide amine were used as a binder and brought from Mc-Growth Chemical Sdn Bhd. Malaysia.

Table 1: Physical and mechanical properties of woven carbon

\begin{tabular}{|c|c|c|}
\hline \multicolumn{2}{|c|}{ and glass fiber } \\
\hline Properties & $\begin{array}{c}\text { Woven } \\
\text { Carbon Fiber }\end{array}$ & $\begin{array}{c}\text { Woven } \\
\text { Glass Fiber }\end{array}$ \\
\hline Type & $\begin{array}{c}\text { Biaxial LT } \\
600\end{array}$ \\
\hline $\begin{array}{c}\text { Areal weight } \\
\text { density }\end{array}$ & $197 \mathrm{~g} / \mathrm{m}^{2}$ & $301 \mathrm{~g} / \mathrm{m}^{2}$ \\
\hline $\begin{array}{c}\text { Fiber } \\
\text { diameter }\end{array}$ & $1.8 \mathrm{~g} / \mathrm{m}^{3}$ & $2.54 \mathrm{~g} / \mathrm{m}^{3}$ \\
\hline $\begin{array}{c}\text { Tensile } \\
\text { Strength }\end{array}$ & $512 \mathrm{KSI}$ & $7 \mu \mathrm{m}$ \\
\hline Strain & $1.5 \%$ & $3.0 \%$ \\
\hline
\end{tabular}

\subsection{Fabrication}

The HFRP composite was designed based on the orientation of fiber, volume fraction of fiber and lamina stacking sequence. Orientation of fiber materials were maintained at $0 / 90^{\circ}$ where fiber volume fraction was expected to achieve 45-55\%. Lamina stacking sequence was taken as follows-[C-G-G-G-C-G-G-G-C]. Carbon fiber was taken as core and skin layers to achieve higher flexural modulus ${ }^{16)}$. Rising number of glass fiber layers in the outer skin significantly reduces the flexural strength ${ }^{17}$. FVF was maintained around 30\% (glass) and 15\% (carbon).

A schematic diagram of vacuum infusion moulding is shown in Fig. 1. There are several steps involve in this fabrication process which are given below:

- Firstly, it is advised to clean the glass mold by using thinner and scraper. Wax was applied on the glass mold and kept 15 minutes for curing. Basically, it provides the easy removal of the composite model after solidification.

- The Sealant tape is applied around the glass mold with at least $50 \mathrm{~mm}$ bigger than the actual laminate size. After that, fiber clothes were laid over the wax inside the sealant tape area according to the stacking sequence.

- Then the polymer mesh and peel ply were placed over fiber clothes. The spiral tube was used to arrange the input and output flow of resin using the sealant tape. Inlet to resin and outlet to vacuum chamberthese two tubes are connected.

- Finally, the vacuum bag is placed on the mold tightly with the help of a sealant tape to avoid any leakage. Once the mold of composite is prepared, the vacuum pump was turn-on to achieve $80 \mathrm{KPa}$ vacuum pressure on the attached pressure gauge. Then the pump is stopped, and the vacuum pressure is 
monitored for 20 minutes to ensure if there is any leakage in the mold. If there is no change in gauge pressure which indicates there is no leakage in the mold, we can proceed to infuse of resin in the mold.

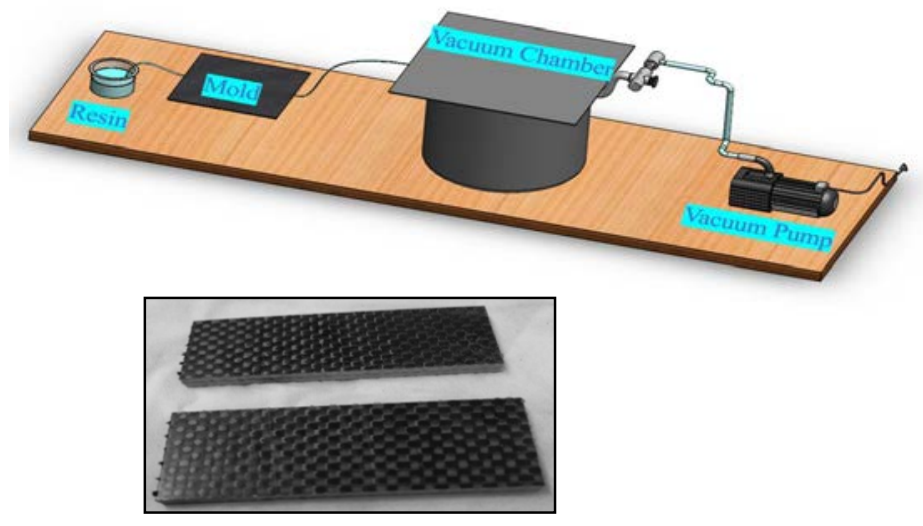

Fig. 1: Schematic diagram of VIM process and fabricated hybrid composites.

\subsection{Coating Preparation}

All the ingredients such as ammonium polyphosphate (APP), boric acid (BA), melamine (MEL), halloysite nanotube (HNT) and zirconium phosphate were mixed together manually according to our formulations given in Table 2 and grounded in a sheer mixer for about 90 seconds to make it homogenous. Expandable graphite (EG) was later added to the mixer and stirred a little with spoon. It is advisable not to grind expandable graphite because bigger the flakes, more the expansion. Then epoxy (BE-188) was added to the mixture and stirred at about $40 \mathrm{rpm}$ for $15 \mathrm{mins}$ using automatic shear mixer CAFRAMO (BDC 6015-220). Later, hardener (H-2310) was added and stirred for another 5 mins at $60 \mathrm{rpm}$. HFRP composite samples were coated using brush (Fig. 2). The samples were kept in the ambient temperature for 1 day for curing.

Table 2: Formulation of coating used in this study

\begin{tabular}{|c|c|}
\hline Materials & Weight (\%) \\
\hline APP & 11.36 \\
\hline BA & 11 \\
\hline Melamine & 5.5 \\
\hline EG & 5.5 \\
\hline HNT & 0.5 \\
\hline ZrP & 0.5 \\
\hline Epoxy & 41.94 \\
\hline Hardener & 19.72 \\
\hline Total & 100 \\
\hline
\end{tabular}

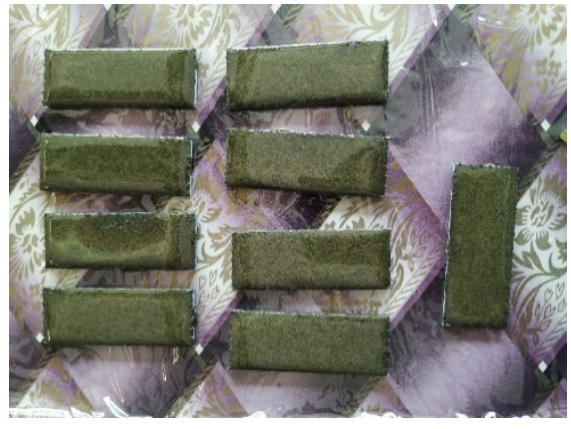

Fig. 2: Coated HFRP composite samples

\subsection{Characterization}

The density was measured by Mettler Toledo AX-205 equipment according to ASTM D 0792 standard. Five samples of $2 \mathrm{~cm} \times 2 \mathrm{~cm}$ were cut from the different section of the panel using diamond abrasive cutter. Average reading of these samples was taken for the accuracy of the test. Fiber volume fraction and void content was measured using burn-off test method according to ASTM D 3171 standards. Samples those were used in density measurement test were cleaned and placed in the carbolite furnace. The temperature of the furnace was set at $600^{\circ} \mathrm{C}$ for 30 minutes for the complete burning of the epoxy matrix. The samples were kept inside the furnace for 2 hours to cool to avoid thermal shocking. The hybrid fibers left inside (Fig. 3) the furnace was weighted in Mettler Toledo AX-205. Fiber volume fraction $\left(\mathrm{V}_{\mathrm{f}}\right)$ and void content $(\mathrm{Vv})$ was measured using the Equations ${ }^{18,19)}$.

$$
\begin{gathered}
\mathrm{V}_{\mathrm{f}}=\frac{n_{s 1} e_{s 1} t e x_{S 1}}{10 t_{c} \rho_{s 1}}+\frac{n_{s 2} e_{s 2} t e x_{s 2}}{10 t_{c} \rho_{s 2}} \\
\mathrm{Vv}=\frac{\rho_{c t-\rho_{c e}}}{\rho_{c t}}
\end{gathered}
$$

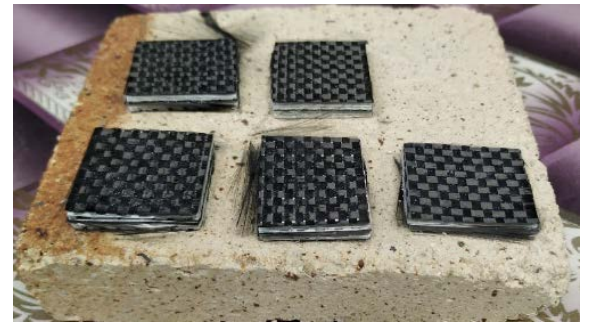

Fig. 3: HFRP composite sample used to measure FVF and void content

The tensile properties were examined using Zwick Roell Amsler HA50 universal testing machine (UTM) according to ASTM D 3039 (Fig. 4 a). A constant rate of $1.27 \mathrm{~mm} / \mathrm{min}$ was applied and stress-strain data was recorded. Flexural test was done at Llyod UTM machine according to ASTM D 0790 standards (Fig. 4 b). The test speed was 1.60 $\mathrm{mm} / \mathrm{min}$. 


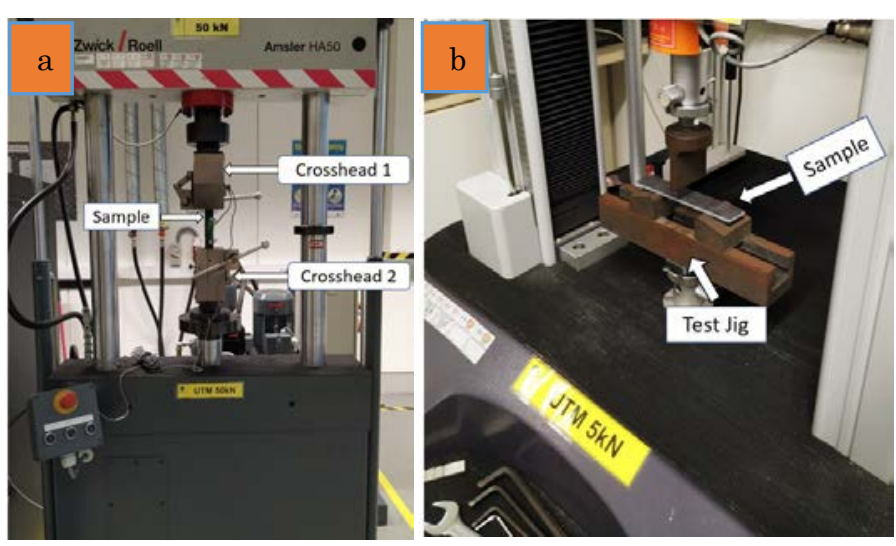

Fig. 4: a) Zwick Roell Amsler HA50 UTM, b) 5KN Llyod UTM machine.

Mazak variaxis 630 CNC machine was used for drilling operation. The machine has maximum spindle speed of $25000 \mathrm{RPM}$ and feed rate of $5000 \mathrm{~mm} / \mathrm{min}$ (Fig. 5 a). HFRP and coated HFRP composites were cut in $70 \mathrm{~mm} \mathrm{x}$ $25 \mathrm{~mm}$ size. HSS drill bit ( $5 \mathrm{~mm}$ diameter and $85^{\circ}$ point angle) was selected in this study (Fig. 5 b). Main drilling parameters are given in Table 3. Delamination factor (DF) was used as drilling performance parameter and calculated as per Equation 3 . Optical microscope was used to capture the drilled hole (entry and exit) images. The image processing was done in Solid-works 2013 software.
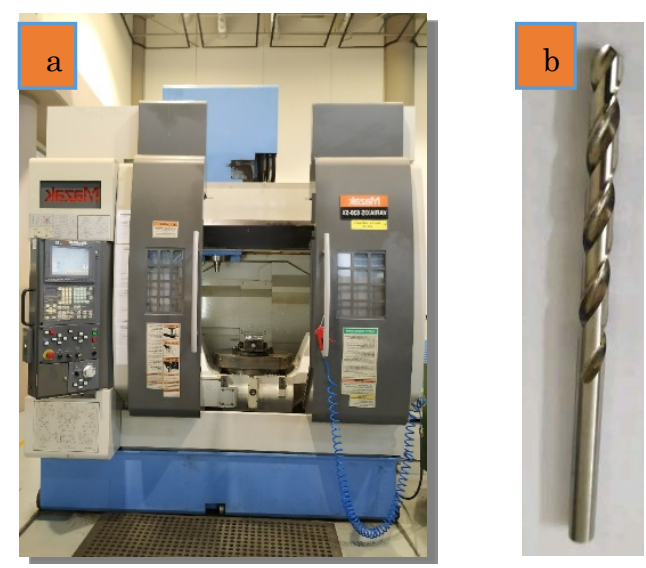

Fig. 5: a) Mazak Variaxis 630 CNC machine, b) HSS drill bit

Table 3: Drilling parameters.

\begin{tabular}{|c|c|c|c|}
\hline $\begin{array}{l}\text { Composite } \\
\text { Type }\end{array}$ & $\begin{array}{c}\text { Thickness } \\
(\mathrm{mm})\end{array}$ & $\begin{array}{l}\text { Feed rate } \\
(\mathrm{mm} / \mathrm{rev})\end{array}$ & $\begin{array}{l}\text { Spindle } \\
\text { speed } \\
(\mathrm{rpm})\end{array}$ \\
\hline HFRP & 3.75 & 0.02 & 3000 \\
\hline $\begin{array}{c}\text { Coated } \\
\text { HFRP }\end{array}$ & 5.75 & 0.08 & 6000 \\
\hline
\end{tabular}

\section{Results and discussions}

In section, properties of HFRP composite and coated HFRP composite are discussed.

\subsection{Physical and mechanical properties}

FVF and void content were found $46 \%$ and $0.391 \%$, respectively. The analysis of the HFRP composite also shows that laminates have been successfully fabricated using the VIM process with less than $5 \%$ of void content ${ }^{20}$. The density of HFRP composite samples was measured by taking specimens from different sides of the panel, and the average density was found $1.68 \mathrm{~g} / \mathrm{cc}$. The average density is less than $1 \%$ of the theoretical density of $1.69 \mathrm{~g} / \mathrm{cc}$. The density of coated HFRP composite was also measured in a similar process and recorded as $1.516 \mathrm{~g} / \mathrm{cc}$, which means approximately $10 \%$ density gets reduced when we apply coating on the surface of the polymer composite.

The tensile strength recorded was compared with the previous literature. Damaged specimen after the tensile test is showing in Fig. 6 (a). Fig. 6 (b), shows the tensile stress vs. tensile strain graph. The average tensile strength and modulus achieved are 441.27 $\mathrm{MPa}$ and 23.25 GPa. The tensile properties of the composite are comparable with their theoretical value, and results are also in agreement with the composite made by Pandya et al. ${ }^{21)}$. The tensile strength of the HFRP composite has sufficiently increased compared to the composite strength reported by Zhang et al. 22). Fiber percentage in the FRP composite directly affects the mechanical strength of the composite ${ }^{23)}$. $433 \mathrm{MPa}$ and $394 \mathrm{MPa}$ tensile strength was reported for G-C and G-C-GC hybrid composite made of land lay-up process by Poyyathappan et al. ${ }^{24)}$. It also indicated that HFRP composite produced with the VIM process has more interlaminar strain energy than composite made with the hand-layup process 25, 26). Mechanical and electrical properties of hybrid fiber composite was investigated by ElMenshawy et al. ${ }^{27)}$ and results showed that placing carbon fiber at the core lowered the tensile strength as glass fiber is more sensitive to crack even in micron size.

(a)

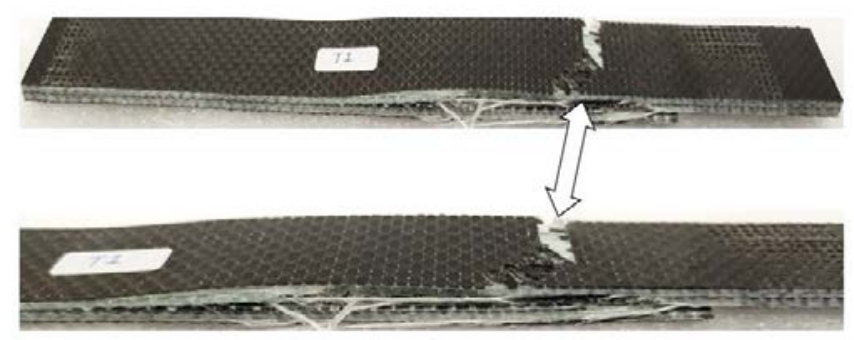

$\mathrm{DF}=\mathrm{D}_{\max } / \mathrm{D}_{\text {hole }}$ 
(b)

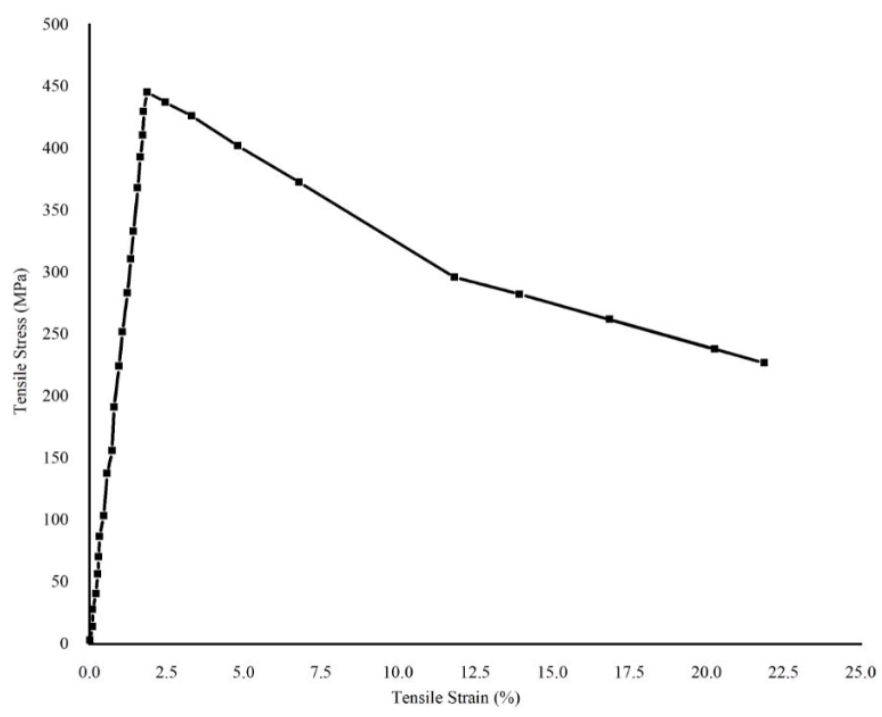

Fig. 6: a) HFRP composite damage during tensile testing b) Tensile properties of HFRP composite

Fig. 7 (a) shows the specimen after the flexural test. Fig.7 (b) shows the flexural properties recorded in the test. Average flexural strength and modulus were recorded as $409 \mathrm{MPa}$ and $20.72 \mathrm{GPa}$, respectively. The test results are comparable with what Lazar et al. ${ }^{28)}$ reported. HFRP composite exhibits higher flexural strength than glass fiber reinforced polymer composite.

(a)

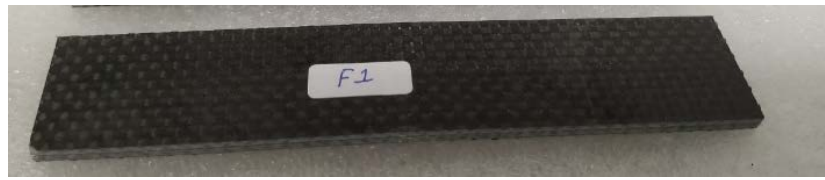

(b)

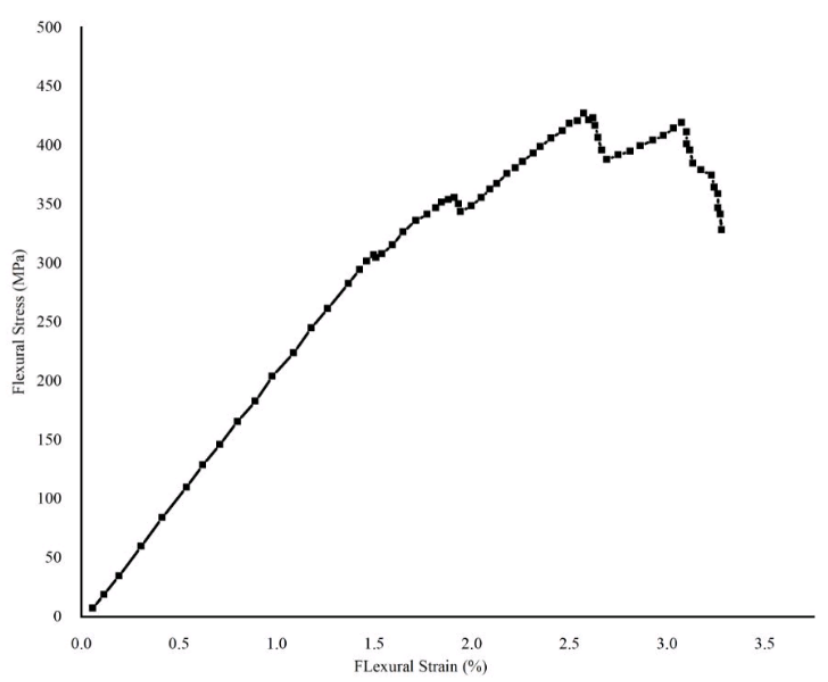

Fig. 7: a) HFRP composite damage during flexural testing b) Flexural properties of HFRP composite

\subsection{Drilling Operation}

Delamination factor (DF) at the entrance and exit for coated and uncoated specimens was calculated, which is shown in Table 4. Maximum DF (1.364) is reported in uncoated HFRP composite when drilling at a spindle speed of 6000 and a feed rate of 0.02 $\mathrm{mm} / \mathrm{rev}$. Minimum DF (1.03) for uncoated samples achieved for a spindle speed of 3000 and feed rate of $0.02 \mathrm{~mm} / \mathrm{rev}$. DF has been found to be increased as the spindle speed increases for uncoated HFRP composite. For entry, DF of uncoated HFRP composite was seen to have no significant effect of increasing feed rate at $3000 \mathrm{rpm}$. However, the exit DF was found declining for this drilling condition. At 6000 rpm, DF (entry) was found increasing with rise of feed rate for uncoated hybrid composite, but exit DF behaved different response. It has been observed that the coating has a substantial effect on the delamination of HFRP composite. For coated HFRP composites, DF at entrance and exit found increasing with rising the speed from $3000 \mathrm{rpm}$ to 6000 $\mathrm{rpm}$. Feed rate significantly influenced the entry DF for both cutting speeds and found increasing with increasing feed rate. On the other hand, the opposite response was seen at the exit. Maximum DF tested for coated samples is 1.22 (S-6000, F-0.08), which is approximately $10.5 \%$ less than maximum delamination occurred in uncoated HFRP composites.

Table 4: Delamination factor (DF) calculated for various drilling parameters

\begin{tabular}{|c|c|c|c|c|c|}
\hline Sl. & $\begin{array}{c}\text { Composite } \\
\text { type }\end{array}$ & $\mathrm{S}$ & $\mathrm{F}$ & $\begin{array}{c}\text { DF } \\
\text { Entry }\end{array}$ & DF Exit \\
\hline 1 & Uncoated & 3000 & 0.02 & 1.036 & 1.18 \\
\hline 2 & Uncoated & 3000 & 0.08 & 1.03 & 1.072 \\
\hline 3 & Uncoated & 6000 & 0.02 & 1.184 & 1.364 \\
\hline 4 & Uncoated & 6000 & 0.08 & 1.204 & 1.286 \\
\hline 5 & Coated & 3000 & 0.02 & 1.02 & 1.16 \\
\hline 6 & Coated & 3000 & 0.08 & 1.038 & 1.08 \\
\hline 7 & Coated & 6000 & 0.02 & 1.14 & 1.206 \\
\hline 8 & Coated & 6000 & 0.08 & 1.178 & 1.22 \\
\hline
\end{tabular}

Fig. 8 shows the microscopic images of the entrance and exit hole for uncoated hybrid composites at various drilling conditions. It can be seen that the quality of the drilled hole was better at inlet compared to the exit of the hole. Mainly delamination type was a form of fiber pull out, uncut fiber, and debonding of the matrix, which can be clearly seen at the exit of a drilled hole. There was crucial improvement found of coating at hybrid composite in terms of drilled hole quality (Fig. 9). The finishing quality was improved at the inlet hole compared to exit. The uncut fiber, fiber pull out, and matrix debonding were the primary reason for higher delamination at the exit for coated hybrid composites, which is clearly shown in Fig. 9. 

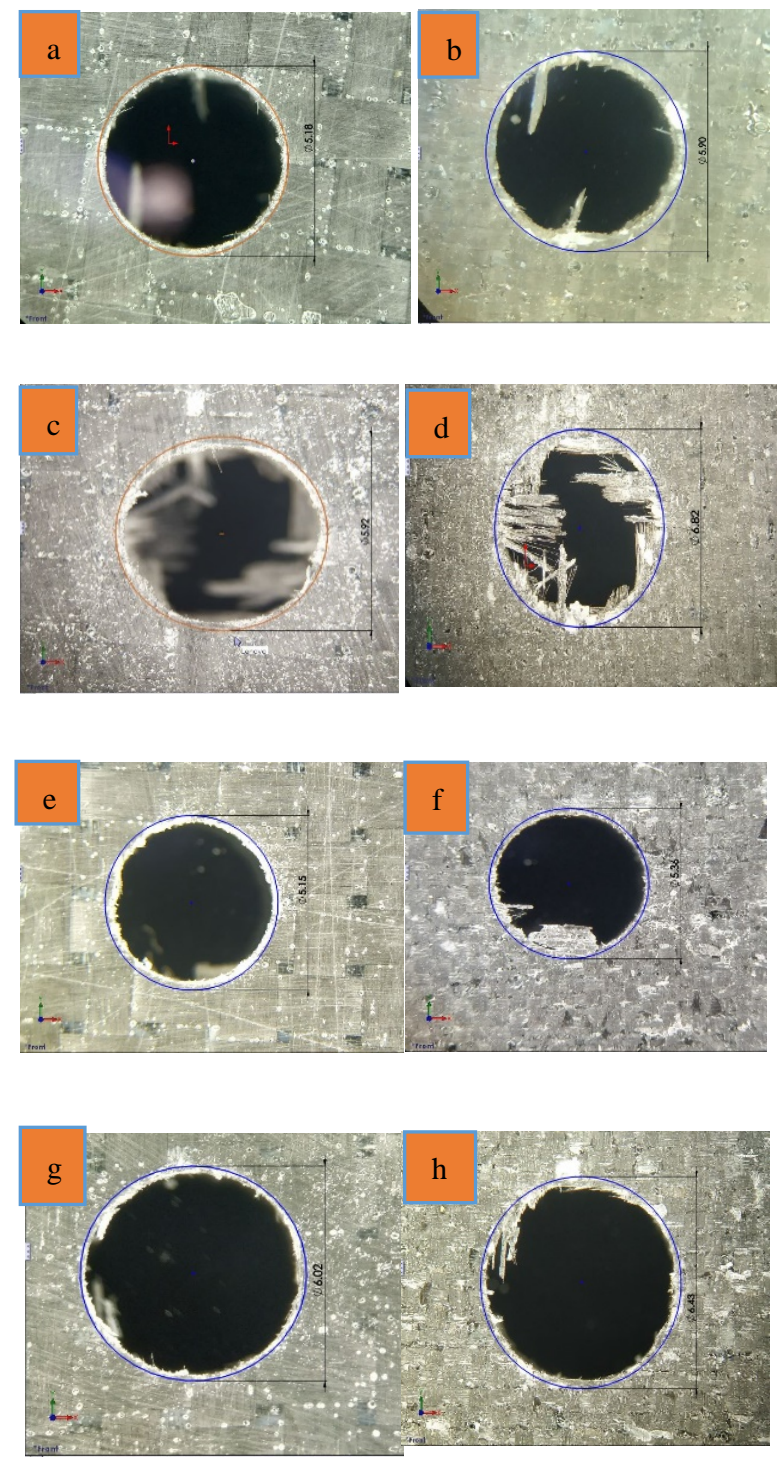

Fig.8: Delamination (a) uncoated S-3000, F-0.02 entry (b) uncoated S-3000, F-0.02 exit (c) uncoated S-3000, F-0.08 entry (d) uncoated S-3000, F-0.08 exit (e) uncoated S-6000, F-0.02 entry (f) uncoated S-6000, F-0.02 exit (g) uncoated S-6000, F0.08 entry (f) uncoated S-6000, F-0.08 exit

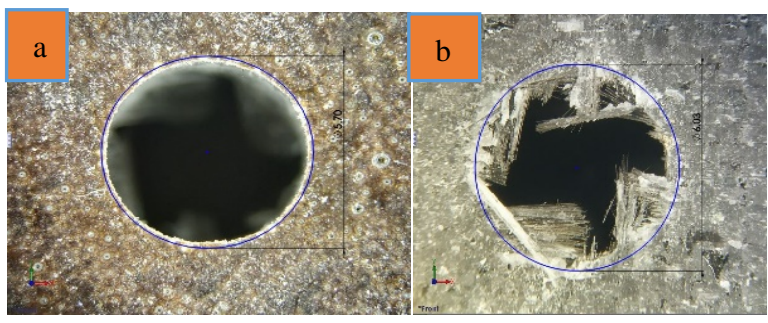

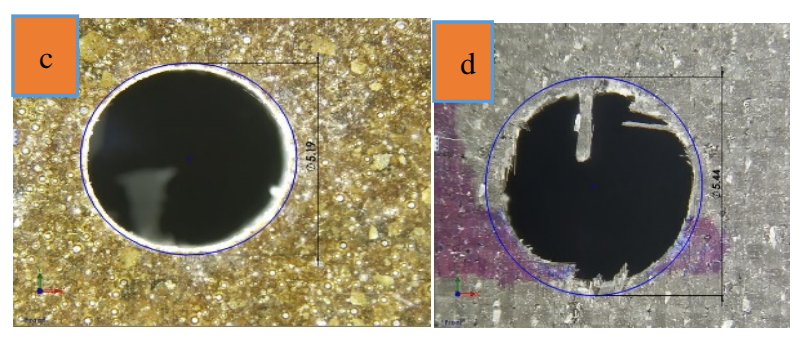
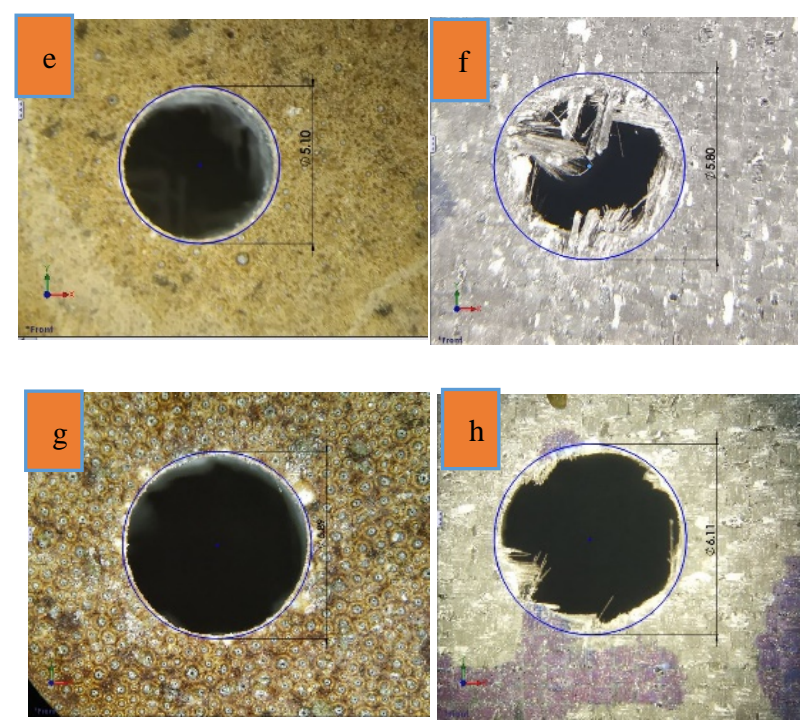

Fig. 9: Delamination (a) coated S-3000, F-0.02 entry (b) coated S-3000, F-0.02 exit (c) coated S-3000, F-0.08 entry (d) coated S-3000, F-0.08 exit (e) coated S-6000, F-0.02 entry (f) coated S-6000, F-0.02 exit (g) coated S-6000, F-0.08 entry (f) coated S-6000, F-0.08 exit

\section{Conclusions}

The primary objective of this research was the investigation of the effects of heat resistant coating on the drilling performance of carbon/glass fibers reinforced epoxy hybrid composite. The hybrid composites were prepared using VIM. The coating was made of APP, BA, EG, and MEL then applied to the hybrid composites. The physical and mechanical properties of the hybrid composite were tested. Results revealed that VIM is efficient in fabricating the composites with less than $5 \%$ void contents, which are a standard requirement for aerospace and automobile industries. FVF was maintained around 46-54\% for the hybrid composites. The tensile and flexural strength of the composite part was tested and found as $441.27 \mathrm{MPa}$ and $409 \mathrm{MPa}$. The elastic modulus for the tensile and flexural test is $23.25 \mathrm{GPa}$ and $20.72 \mathrm{GPa}$, respectively. There was a significant effect seen on density for coated hybrid composite, which showed approximately 10\% reduction compared to the uncoated HFRP composite. For the drilling point of view, the delamination factor was found higher with increasing spindle speed and feed rate. The exit side of the drilled hole showed more delamination than the entry. Coated specimens were better in terms of producing 
less delamination than the uncoated specimens. Lowest delamination was observed for S-3000 RPM and F- 0.02 $\mathrm{mm} / \mathrm{rev}$ at the entry side of the coated HFRP composite. Whilst highest delamination is observed for S- 6000 RPM and F- $0.02 \mathrm{~mm} / \mathrm{rev}$ at the exit side of uncoated HFRP composite. There was significant improvement was found at the entry of the hole in terms of surface finishing due to coating. However, exit hole quality was not good for both types of hybrid composites. Mainly delamination was found in the form of fiber pull out, uncut fibers, and matrix debonding. Thus, the coating was not able to enhance the quality of the drilled hole for tested hybrid composites. However, the impact of other drilling parameters such as thrust force and drilling temperature can be examined in the future for coated hybrid composites.

\section{Acknowledgements}

The authors would like to express their thankfulness to the Department of Mechanical Engineering, Universiti Teknologi PETRONAS (UTP) and center of Advanced Functional Materials (AFM) for providing all facilities required for experimentation and testing. The authors also want to appreciate the financial support given through FRGS-015MAO-081 research grant by MOHE, Malaysia.

\section{Nomenclatures}

FRP- Fiber Reinforced Polymer

HFRP- Hybrid Fiber Reinforced Polymer

CFRP- Carbon Fiber Reinforced Polymer Composite

GFRP- Glass Fiber Reinforced Polymer Composite

EG- Expandable Graphite

APP-Ammonium Polyphosphate

BA- Boric Acid

MEL- Melamine

VIM- Vacuum Infusion Molding

FVF- Fiber Volume Fraction

$\mathrm{n}_{\mathrm{s}}=$ number of plies

$\mathrm{e}_{\mathrm{s}}=$ number of yarns

$\rho=$ density of fiber

tex $_{\mathrm{s}}=$ linear density in $\mathrm{g} / \mathrm{km}$

$\mathrm{t}_{\mathrm{c}}=$ final composite thickness in $\mathrm{mm}$

$\rho_{\mathrm{ct}}=$ theoretical density of the composite

$\rho_{\mathrm{ce}}=$ experimental density of the composite

$\mathrm{DF}=$ Delamination factor

$\mathrm{S}=$ Spindle speed

$\mathrm{F}=$ Feed rate

\section{References}

1) Nishizaki, I., et al. A case study of life cycle cost based on a real FRP bridge. in Third international conference on FRP composites in civil engineering (CICE 2006). 2006. Miami:[sn].

2) Sosiati, H., Y.A. Shofie, and A.W. Nugroho, Tensile properties of Kenaf/E-glass reinforced hybrid polypropylene (PP) composites with different fiber loading. EVERGREEN Joint
Journal of Novel Carbon Resource Sciences \& Green Asia Strategy, 2018. 5(2): p. 1-5.

3) Maurya, M., N.K. Maurya, and V. Bajpai, Effect of $\mathrm{SiC}$ reinforced particle parameters in the development of aluminium based metal matrix composite. EVERGREEN Joint Journal of Novel Carbon Resource Sciences \& Green Asia Strategy, 2019. 6: p. 200.

4) Khashaba, U. and A. El-Keran, Drilling analysis of thin woven glass-fiber reinforced epoxy composites. Journal of Materials Processing Technology, 2017. 249: p. 415-425.

5) El-Sonbaty, I., U. Khashaba, and T. Machaly, Factors affecting the machinability of GFR/epoxy composites. Composite structures, 2004. 63(3-4): p. 329-338.

6) Jagannatha, T., et al. Optimization of machining parameters of hybrid fiber reinforced polymer composites using design of experiments. in AIP Conference Proceedings. 2019. AIP Publishing LLC.

7) Kozłowski, R. and M. Władyka - Przybylak, Flammability and fire resistance of composites reinforced by natural fibers. Polymers for Advanced Technologies, 2008. 19(6): p. 446-453.

8) Lau, D., et al., Long term performance and fire safety aspect of FRP composites used in building structures. Construction and building materials, 2016. 126: p. 573-585.

9) Papa, I., et al., Carbon/glass hybrid composite laminates in vinylester resin: Bending and low velocity impact tests. Composite Structures, 2020. 232.

10) Nagarajan, V., V. Kumar, and V. Samsingh, Artificial intelligence modelling and analysis of pivotal parameters in drilling hybrid fiber composite (HFC). FME Transactions, 2017. 45(4): p. 641-646.

11) Geng, D., et al., Delamination formation, evaluation and suppression during drilling of composite laminates: $A$ review. Composite Structures, 2019.

12) Gaitonde, V., et al., Analysis of parametric influence on delamination in high-speed drilling of carbon fiber reinforced plastic composites. Journal of materials processing technology, 2008. 203(1-3): p. 431-438.

13) Feito, N., et al., Experimental and numerical analysis of step drill bit performance when drilling woven CFRPS. Composite Structures, 2018. 184: p. 1147-1155.

14) Maoinser, M.A., F. Ahmad, and S. Sharif. Effects of Cutting Parameters on Hole Integrity when Drilling GFRP and HFRP Composites. in Advanced Materials Research. 2014. Trans Tech Publ. 
15) Higuchi, R., et al., Experimental and numerical investigations on push-out delamination in drilling of composite laminates. Composites Science and Technology, 2020. 198: p. 108238.

16) Durao, L.M.P., Machining of Hybrid Composite in Mechanical Engineering and Industrial Management 2005, University of Porto

17) Jesthi, D.K. and R.K. Nayak, Influence of glass/carbon fiber stacking sequence on mechanical and three-body abrasive wear resistance of hybrid composites. Materials Research Express, 2020. 7(1).

18) Abraham, D., S. Matthews, and R. McIlhagger, A comparison of physical properties of glass fibre epoxy composites produced by wet lay-up with autoclave consolidation and resin transfer moulding. Composites Part A: Applied Science and Manufacturing, 1998. 29(7): p. 795-801.

19) Christensen, R.M., Mechanics of composite materials. 2012: Courier Corporation.

20) Astrom, B.T., Manufacturing of polymer composites. 1997: CRC press.

21) Pandya, K.S., C. Veerraju, and N. Naik, Hybrid composites made of carbon and glass woven fabrics under quasi-static loading. Materials \& Design, 2011. 32(7): p. 4094-4099.

22) Zhang, J., et al., Hybrid composite laminates reinforced with glass/carbon woven fabrics for lightweight load bearing structures. Materials \& Design (1980-2015), 2012. 36: p. 75-80.

23) Mahyudin, A., et al., Mechanical Properties and Biodegradability of Areca Nut Fiber-reinforced Polymer Blend Composites. Evergreen, 2020. 7(3): p. 366-372.

24) Poyyathappan, K., et al., Experimental Analysis and Comparative Mechanical testing on Glass- Carbon Hybrid Composites. Materials Today-Proceedings, 2019. 16: p. 612-620.

25) Atas, C., et al., An experimental investigation on the low velocity impact response of composite plates repaired by VARIM and hand lay-up processes. Composite Structures, 2011. 93(3): p. 1178-1186.

26) Soutis, C., Fibre reinforced composites in aircraft construction. Progress in aerospace sciences, 2005. 41(2): p. 143-151.

27) El-Menshawy, O.F., et al., Electrical and Mechanical Performance of Hybrid and Nonhybrid Composites. International Journal of Engineering, 2019. 32(4): p. 580-586.

28) Lazar, M.-B. and P. Xirouchakis, Experimental analysis of drilling fiber reinforced composites. International Journal of Machine Tools and Manufacture, 2011. 51(12): p. 937-946. 